\title{
Asymmetric demand information in uniform and discriminatory call auctions: an experimental analysis motivated by electricity markets
}

\author{
KLAUS ABBINK*, JORDI BRANDTS**, and TANGA MCDANIEL*** \\ * $\quad$ University of Nottingham \\ ** Institut d'Anàlisi Econòmica (CSIC), Barcelona \\ *** University of Cambridge
}

February 2002

\begin{abstract}
We study the outcomes of experimental multi-unit uniform and discriminatory auctions with demand uncertainty. Our study is motivated by the ongoing debate about market design in the electricity industry. Our main aim is to compare the effect of asymmetric demand-information between sellers on the performance of the two auction institutions. In our baseline conditions all sellers have the same information, whereas in our treatment conditions some sellers have better information than others. In both information conditions we find that average transaction prices and price volatility are not significantly different under the two auction institutions. However, when there is asymmetric information among sellers the discriminatory auction is significantly less efficient. These results are not in line with the typical arguments made in favor of discriminatory pricing in electricity industries; namely, lower consumer prices and less price volatility. Moreover, our results provide some indication that discriminatory auctions reduce technical efficiency relative to uniform auctions.
\end{abstract}

\section{Keywords}

Experiments, asymmetric information, discriminatory price auctions, uniform price auctions, electricity industries.

\section{JEL Classification Codes}

C90, D43, D82, K23, L94, Q41

\section{Acknowledgements}

We are indebted to David Rodríguez for valuable research assistance. We also thank Paul Pezanis-Christou, Richard Green, David Newbery, Nat Wilcox, and two anonymous referees for valuable comments. Financial support by the European Union from a TMR-ENDEAR network grant (FMRX-CT98-0238), from the Spanish Ministerio de Educación y Cultura (PB98-0465) and ESRC (R000-238563) is gratefully acknowledged. Remaining errors are ours.

Authors

\begin{tabular}{|c|c|c|}
\hline Klaus Abbink & Jordi Brandts & Tanga McDaniel \\
\hline School of Economics & Institut d'Anàlisi Econòmica CSIC & Department of Applied Economics \\
\hline The University of Nottingham & Campus UAB & University of Cambridge \\
\hline University Park & 08193 Bellaterra & Austin Robinson Building \\
\hline Nottingham, NG7 2RD & Spain & Sidgwick Avenue \\
\hline United Kingdom & & Cambridge, CB3 9DE \\
\hline phone $+44-115-9514768$ & phone $+34-93-5806612$ & phone $+44-1223-335272$ \\
\hline fax $+44-115-9514591$ & fax $+34-93-5801452$ & fax $+44-1223-335299$ \\
\hline klaus.abbink@nottingham.ac.uk & brandts@cc.uab.es & tm223@econ.cam.ac.uk \\
\hline
\end{tabular}




\section{Introduction}

Liberalization in utility industries began in the 1980s and gained speed and complexity throughout the 1990s. Around the world the process has involved a movement away from centralized planning of infrastructure and supply towards more market based principles for guiding agents' interactions. Some of the most diverse market organizations have arisen in the electricity industry where governments, regulators and industry participants have recognized the myriad of intricate details that must be reconciled in order to make decentralized trading efficient. However, one of the important aspects that is often overlooked is the possible interaction between information asymmetries among heterogeneous sellers and the rules governing the market.

In this paper we use laboratory experiments to study the outcomes of uniform price and discriminatory price call-auctions when different sellers are asymmetrically informed about market demand. These two institutions are natural choices for our purpose as they correspond to the auction formats most closely related to the actual institutions used in electricity spot markets (i.e., power pools and balancing mechanisms). The two remuneration schemes, uniform and discriminatory, represent two alternative ways of paying generators who are scheduled to operate in a given period of the day.

In many respects daily demand changes are predictable, yet something as simple as a popular football match can raise demand enough to necessitate more capacity than estimated a day in advance. In the England and Wales market the estimation that was once done primarily by the transmission operator and owner, National Grid Company, is now a more decentralized activity performed largely at the company level. Some companies have claimed that human resources have increased four-fold in their information technology departments to accommodate new trading and demand estimation requirements under NETA. ${ }^{1}$

Electricity industries are characterized by a mix of agent types. Agents range from the owner of a single small generation station, to the vertically integrated generation-plussupply company, to the multi-utility with ownership of generation and supply assets in addition to interest in gas and trading companies. As Kahn et al. (2001) suggest, the resource burden of demand estimation will vary among firms. Information gathering may be more costly for smaller less integrated companies, for example, and knowing the implications of this is important in a world where it is politically and environmentally desirable to encourage certain agent types (e.g., renewables and combined-heat and power) to remain in the market.

\footnotetext{
1 "How well is NETA doing," Regulation Initiative Workshop, London Business School, October 17, 2001.
} 
Informational asymmetries have differential consequences for generator types more generally because of the relationship between costs and running time. High cost generators produce less often and their profitability is greatly influenced by realized demand levels. If informational differences among these types of sellers have divergent consequences under alternative market institutions this will have consequences for overall market efficiency and seller profitability. It is this situation that our experiments best describe. Our main finding is that in treatments with asymmetric information the uniform price auction is more efficient than the discriminatory auction. The relative inefficiency of the discriminatory auction is not due to higher average prices but instead to higher marginal or cut-off prices. These higher cut-off prices benefit the high cost generators who obtain more profits relative to the uniform treatment. We also find some indication that discriminatory auctions reduce technical efficiency relative to uniform auctions but this result is not significant.

\section{Background}

Because of the complexity and diversity of energy markets there is a general lack of understanding about which factors are most important for achieving a sustainable competitive market. The influence of certain factors is rather clear; for instance, surplus transmission and generation capacity are considered as highly desirable in so far as they improve security of supply and better enable the monitoring of dominant players' behavior. Some other issues are less well understood. For instance, how should generators be paid for the power they sell? One approach is to pay all generators the same per unit price (equivalent to the bid of the most expensive station required to meet demand); another is to pay each generator its own bid price for the power it sells.

The choice between uniform and discriminatory bidding rules was discussed and heatedly debated in the England and Wales market after the government along with the industry regulator announced a review of the electricity trading arrangements in 1997. The power pool and associated uniform clearing price which had been in place since the industry was privatized in 1990 were to be replaced with bilateral contract markets and a last minute balancing mechanism to reconcile demand and supply differences. These new rules, which have become known as the New Electricity Trading Arrangements or NETA, came into effect on March 27, 2001. ${ }^{2}$ The uniform price of the former pool has

\footnotetext{
${ }^{2}$ See Office of Electricity Regulation (Offer, 1998) for discussions of the review process and Offer (1999) for the NETA design.
} 
been replaced with discriminatory prices in the contract markets as well as in the balancing mechanism. ${ }^{3}$

A similar debate over payment rules arose in California when in November 2000 a panel of renowned economists was commissioned to comment on whether or not California should switch from uniform pricing in the Power Exchange to pay-bid (i.e., discriminatory) pricing. The California panel unanimously favored a uniform price. They stated that:

"...our response is that the expectation behind the proposal to shift from uniform to as-bid pricing- that it would provide purchasers of electric power substantial relief from the soaring prices of electric power such as they have recently experienced- is simply mistaken." (Kahn et al. (2001), p2)

The panel claimed that the use of pay-bid would weaken competition in generation, impede capacity expansion, and result in inefficient dispatch. These conclusions are at least partly based on the fact that profitability under discriminatory pricing is contingent on generators' ability to predict the marginal price (which depends on demand), and that this ability will vary among firms. In England and Wales and in California the policy makers and consumer groups who favored discriminatory remuneration argued on the basis of similar expectations. Relative to uniform prices they expected: reduced market power, lower consumer prices, reduced collusion potential, and reduced price volatility.

Green and McDaniel (1999) model the two payment schemes in the context of the England and Wales market. Using a two-stage model with forward and spot trading they first derive a revenue-equivalence result for the spot market, ${ }^{4}$ but secondly they show that bidding strategies require more information about quantities contracted in forward rounds under the discriminatory method. They conclude that this could disadvantage smaller or entrant agents.

The issue we are interested in, the interaction between information asymmetries and market institutions, is difficult to quantify on the basis of information from the field as measures of such informational differences require data that is commercially confidential, strategic and potentially highly subjective. However, using laboratory experiments the importance of information can still be addressed, since we can separately study environments with different market institutions and different information conditions.

\footnotetext{
${ }^{3}$ Approximately $95 \%$ of electricity trades in England and Wales are now via bilateral contracts between retail suppliers and generators. Trading in the balancing mechanism accounts for the remainder of trades and this trading is conducted by the System Operator, National Grid Company. "Last minute" is actually $31 / 2$ hours prior to real time.

${ }^{4}$ With single unit demands, Vickrey's (1961) revenue equivalence theorem predicts this result.
} 
Hence, experiments may help to curtail the political and financial expenses of deregulation by uncovering potential distortions in proposed market designs before they are enacted.

\section{Previous Experimental Studies}

Experimentalists' interest in the electricity industry is growing but there are so far only a few available papers on this theme. Several papers have arisen from consulting projects in Arizona, and other groups are currently delving into this topic.

Some of this research has focused on factors that mitigate market power (e.g., Rassenti, Smith and Wilson (2000)) with significant interest spawning from events in the England and Wales market, particularly NETA (e.g., Rassenti, Smith and Wilson (2001), and Staropoli et al. (2000)). Rassenti et al. (2000) found that market power is associated with high and variable prices, but this outcome can be neutralized with demand side bidding. Efficiency in their design approached 100 percent in treatments combining demand side bidding and no market power. As in Rassenti et al. (2000), Rassenti et al. (2001) use a network design with 3 nodes and sellers located at different points on the network. They find that, relative to uniform price auctions, the discriminatory auction results in higher (though less volatile) prices and less efficiency. Prices observed in the discriminatory auction without market power were as high as a uniform price auction with market power. In their experiment sellers had full supply side information (capacity, sellers' marginal costs and network positions), but demand was unknown to all subjects.

Using the England and Wales market as a reference, Staropoli et al. (2000) consider an environment in which sellers can behave strategically with respect to both price bids and quantity bids. In the latter case, firms withhold some of their capacity from the market in efforts to drive up prices. Using a uniform price auction, they find substantial mark-ups and inefficient dispatch in treatments with and without market power, and individual efforts to withhold capacity to increase prices were not successful in either case.

With multi-unit demand auctions, it is difficult to make general theoretical statements comparing auction institutions. This is summed up well by Ausubel and Cramton (1998), "Considering the twin objectives of allocative efficiency and revenue maximization, we find that the ranking [between uniform and discriminatory auction] is inherently ambiguous... the choice ought to be viewed as an empirical question that depends on the actual nature of demands." Experiments seem to confirm this conclusion. ${ }^{5}$ Smith (1967) is one of the first experimental papers to compare discriminatory and uniform price

\footnotetext{
${ }^{5}$ In the less industry-specific literature on multi-unit auctions typically buyers rather than sellers are the bidders.
} 
auctions. Using treasury auctions as a context and allowing each bidder to demand two units he finds that bidding behavior is more volatile in the uniform price auction. Revenues in the experiments depended on the proportion of rejected bids; if the proportion was 'low to moderate', the uniform auction produced higher revenues. Miller and Plott (1985) find that prices are typically near the competitive equilibrium in both uniform and discriminatory-price auctions. Goswami, Noe and Rebello (1996) allow preplay communication between the bidders before the auction and find that collusive (low revenue) outcomes are more likely to arise in a uniform than in a discriminatory price auction. On the other hand, Abbink, Brandts, and Pezanis-Christou (2002), studying a common value setting, detect a revenue advantage for the uniform auction over the discriminatory format. ${ }^{6}$

To our knowledge none of the existing studies tackles an environment with asymmetric information on market demand. In the present paper, we compare the two most prominent trading mechanisms, the uniform price auction, which can be seen as a stylized version of the former Pool in England and Wales, and the discriminatory auction, which has been discussed in connection with the reform of the electricity trading institutions in California and is used in the balancing mechanism under NETA. Both mechanisms we study involve one-sided bidding, where the demand side is computerized and represented by demand functions. ${ }^{7}$

\section{Experimental Design}

Our goal was to design an environment simple enough to allow experimentation, but which captures the most important features characterizing the environment of an electricity trading institution. ${ }^{8}$ Below we describe and discuss these design choices in detail.

\footnotetext{
${ }^{6}$ Different set-ups are discussed in Alsemgeest, Noussair, and Olson (1998), Kagel and Levin (2001), and Manelli Sefton and Wilner (2000). In the former two, revenue rankings and effeciency losses can be partly attributed to the incentives in multi-unit auctions for demand reduction.

${ }^{7}$ One of the goals of NETA was to introduce more demand-side participation. Retailers enter into contracts with generators in the bilateral markets and can participate in the balancing mechanism. So far demand-side participation in the balancing mechanism has been very limited.

${ }^{8} \mathrm{We}$ do not incorporate line constraints or market power (both of which are important characteristics of electricity industries) because we want to focus solely on the influence of information differences under the two auction mechanisms. The interaction of line constraints and/or market power with informational asymmetries might well lead to different results, and we view this as an interesting topic for future research.
} 


\subsection{Costs, Demand, and Information Settings}

In the absence of contractual obligations that influence running decisions, a station's start-up costs are a primary determinant of desired load, i.e., the proportion of hours throughout the day that a station would like to generate. The high cost of restarting a nuclear plant makes it attractive to run them almost continuously throughout the day and these stations are unlikely to set the price of electricity unless demand is exceptionally low. At the other extreme are open-cycle-gas-turbines which can be turned on according to the level of demand at intervals within the day. Start-up costs comprise an element of a plant's 'avoidable costs'; these are not fixed costs for a station because they are not incurred if there is no production. An operator incurs the full start-up costs if any units are produced at all (i.e., the cost is the same if the station produces one unit or all units up to capacity), but no costs if production is zero; This is the interpretation of avoidable costs offered by Telser (1978) and the one which we adopt for our experiments. Sellers incur only avoidable and marginal costs in our design.

The higher the demand in a period, the more expensive are the marginal cost of stations required to generate in those periods. In each of our experimental groups there are always two low cost and two high cost sellers, and subjects remained the same type throughout the experiment. Costs were chosen to qualitatively mimic baseload versus peakload generators in the electricity industry. Baseload generators have high avoidable costs and low marginal costs while peakload generators have low avoidable costs and high marginal costs.

The total cost structure for the two generator types is shown in Table 1. Each seller has 4 units she can sell in each period: baseload sellers have avoidable costs of 13 , two units with marginal costs of 1 , and two with marginal costs of 5; peakload sellers have an avoidable cost of 4 , two units with marginal cost of 21 and two units with marginal costs of $23{ }^{9}$

In the presence of avoidable costs the technically optimal way of sharing the production of different total output levels among different production units does not simply correspond to the ordering of the marginal cost levels. Rather, one has to consider the cost structure as a whole. For the cost structure used in our experiment, the optimal allocations are as shown in table 2. The second and third column of the table show how the quantities should be allocated to the two firms within either of the two categories of baseload and peakload producers. For instance, a quantity of 6 units is optimally

\footnotetext{
${ }^{9}$ In the instructions subjects were only given total cost information. We feel that this is the most natural way of presenting cost information. Marginal and average costs could easily be inferred from the total cost table, but were not given explicitly. Nevertheless, in the presence of avoidable costs a sound bidding strategy on the basis of marginal costs is not straightforward. An English translation of the instructions can be found in Appendix I.
} 
produced by one of the baseload producers producing 4 units and the other 2 or, alternatively, both of them producing 3 units, with both peakload producers producing nothing. ${ }^{10}$ Observe that optimal scheduling sometimes requires a rather high degree of coordination. For example, if between 9 and 11 units are sold, only one of two identical peakload producers can produce and if 4 or fewer units are sold, only one producer is active.

Table 1: Avoidable, Total, and Marginal and Average costs for each seller type*

\begin{tabular}{c|cccc|cccc}
\hline & \multicolumn{5}{|c|}{ Baseload } & \multicolumn{4}{c}{ Peakload } \\
Units & AvoiC & TC & MC & AC & AvoiC & TC & MC & AC \\
\hline 0 & 0 & 0 & 0 & 0 & 0 & 0 & 0 & 0 \\
1 & 13 & 14 & 14 & 14 & 4 & 25 & 25 & 25 \\
2 & 13 & 15 & 1 & 7.5 & 4 & 46 & 21 & 23 \\
3 & 13 & 20 & 5 & 6.67 & 4 & 69 & 23 & 23 \\
4 & 13 & 25 & 5 & 6.25 & 4 & 92 & 23 & 23 \\
\hline
\end{tabular}

* AvoiC stands for avoidable cost, TC for total cost, MC for marginal cost and AC for average cost.

The supply function derived from the firms' cost functions exhibits also some nonstandard features. In the presence of avoidable costs, the supply function cannot be straightforwardly obtained by plotting the marginal cost function. Rather, the total supply for a given price needs to be taken directly from computing the maximal number of units that firms are willing to sell at that price. ${ }^{11}$ The lowest price at which a positive quantity can profitably be sold is 6.25 , as this is the lowest possible price that covers the average production costs at any quantity. At 6.25 , both baseload producers are willing to sell all their units, i.e. a total of 8 . Notice that no seller would be willing to sell less than his full capacity. At prices above 6.25, the baseload producers may be willing to sell fewer units, but still the maximum quantity they would offer is 8 . The next highest price at which more than 8 units can profitably be sold is 23 , at which both peakload producers are willing to sell all their units. At all prices above 23 the supply is also 16, since all firms produce profitably at their capacity limits. Thus, we obtain the supply curve as depicted in figure 1.

The shape of the demand curve in our design is very similar to Rassenti, Smith, and Wilson (2000); there is a sizeable inelastic portion of demand at a high price of 100 with two "interruptible" steps at 55 and 30. Each of these steps corresponds to 2 units. This downward sloping demand curve captures some of the essential features of the industry demand. The "steps" on the demand curve always remain the same and are known by all

\footnotetext{
${ }^{10}$ Observe that the minimal average cost schedule has two local minima.

${ }^{11}$ This representation is like the one used by Van Boening and Wilcox (1996).
} 
producers. In contrast, the inelastic portion, which we refer to as $X$, is stochastic. The elasticity of demand for electricity is very low and as such could be represented vertically without loss of generality. However, a downward sloping though still inelastic demand curve better represents actual circumstances: very larger consumers have fairly predictable demands and are willing to be interrupted when prices rise, but residential demands are more volatile. The value of $X$ varies randomly each period between 5 and 10, so maximum demand varies with any value between 9 and 14, inclusive, with the same probability of being chosen. ${ }^{12}$ Figure 1 shows the demand configuration for the minimum and maximum basic demand $(X=5$ and $X=10)$.

Table 2: Optimal scheduling for given total quantities

\begin{tabular}{ccccc}
\hline Quantity & $\begin{array}{c}\text { Quantity } \\
\text { Baseload } \\
\text { producers }\end{array}$ & $\begin{array}{c}\text { Quantity } \\
\text { Peakload } \\
\text { producers }\end{array}$ & $\begin{array}{c}\text { Minimal total } \\
\text { costs }\end{array}$ & $\begin{array}{c}\text { Minimal } \\
\text { average costs }\end{array}$ \\
\hline 1 & $1+0$ & $0+0$ & 14 & 14.00 \\
2 & $2+0$ & $0+0$ & 15 & 7.50 \\
3 & $3+0$ & $0+0$ & 20 & 6.67 \\
4 & $4+0$ & $0+0$ & 25 & 6.25 \\
5 & $4+1$ & $0+0$ & 39 & 7.20 \\
6 & $4+2(3+3)^{*}$ & $0+0$ & 40 & 6.67 \\
7 & $4+3$ & $0+0$ & 45 & 6.43 \\
8 & $4+4$ & $0+0$ & 50 & 6.25 \\
9 & $4+4$ & $1+0$ & 75 & 8.33 \\
10 & $4+4$ & $2+0$ & 96 & 10.62 \\
11 & $4+4$ & $3+0$ & 119 & 11.83 \\
12 & $4+4$ & $4+0(2+2)^{*}$ & 142 & 12.69 \\
13 & $4+4$ & $3+2$ & 165 & 13.43 \\
14 & $4+4$ & $4+2(3+3)^{*}$ & 188 & 14.07 \\
15 & $4+4$ & $4+3$ & 211 & 14.63 \\
16 & $4+4$ & $4+4$ & 234 & \\
\hline
\end{tabular}

* In brackets are alternative schedules with the same minimal costs

When players are asymmetrically informed about demand, this asymmetry is with respect to $X$. Low cost sellers know the value of $X$ each period with certainty while high cost sellers are given a noisy signal. ${ }^{13}$ Because of the relative cost structures, low cost

\footnotetext{
${ }^{12}$ Demand on a typical winter day in England and Wales ranges approximately between 30 and $50 \mathrm{GW}$. Our demand range from 9 to 14 represents this relationship between seasonal minimum and maximum demand; i.e., minimum demand is approximately 0.6 times maximum demand. The experiment necessarily exaggerates demand fluctuations over short periods, however. The amount of spare capacity in our design (14 percent) is broadly in line with much of Europe.

${ }^{13}$ We could have chosen to have one informed baseload and one informed peakload seller but because baseload sellers should always be able to sell their units for any level of demand in our design, their profitability is less sensitive to demand information than for peakload sellers. Thus, we believe this design is more informative.
} 
generators should always want to run and are generally less sensitive to realized demand. We, therefore, chose to always have them perfectly informed.

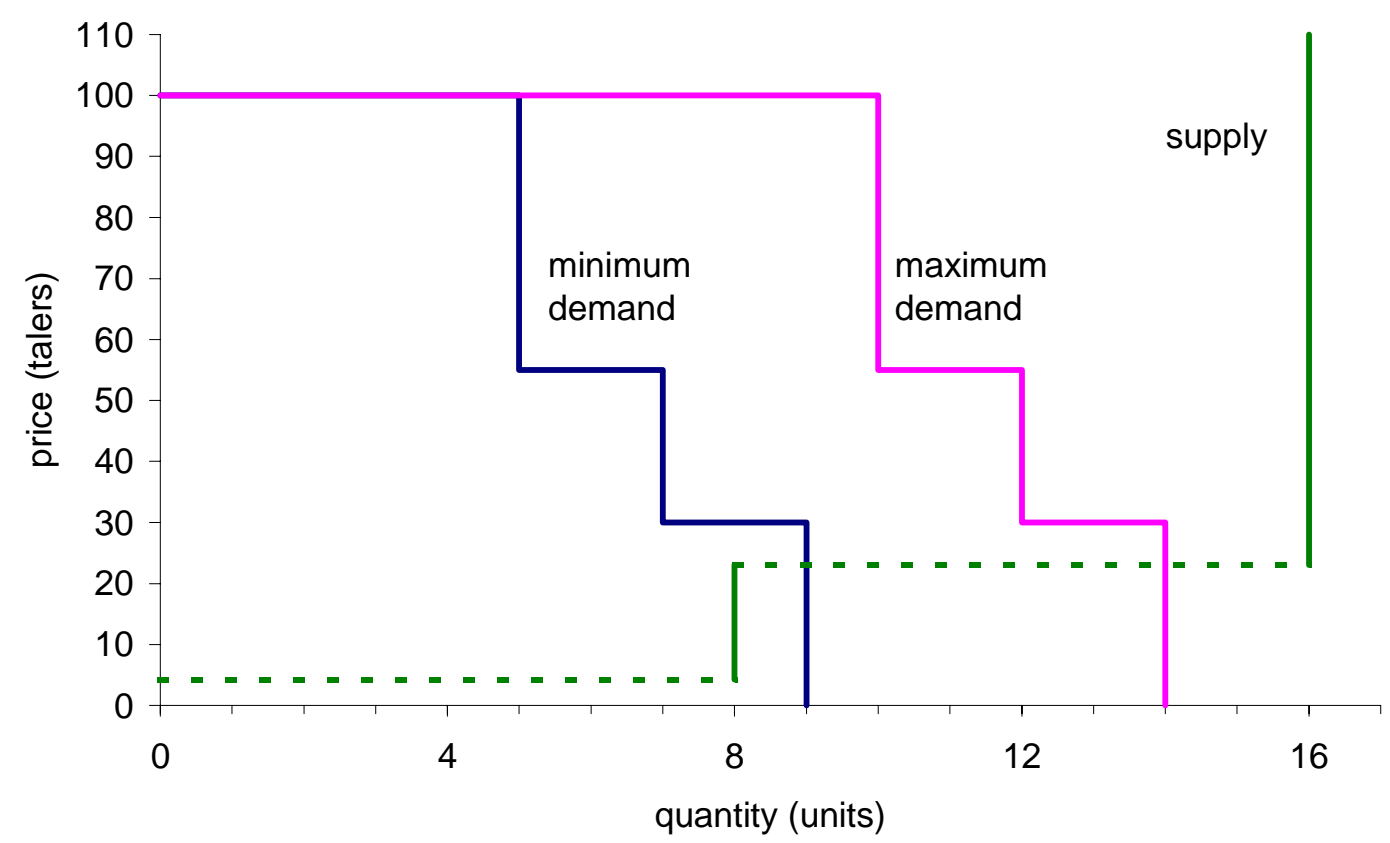

Figure 1: Supply and demand curve under minimum and maximum $X$ configuration

In our asymmetric information settings, peakload sellers receive a noisy estimate of demand in each period. There are two demand signals: high ( $X$ is between 8 and 10) and low ( $X$ is between 5 and 7). A high signal means there is an $80 \%$ chance that demand is between 8 and 10 (20\% that it is between 5 and 7) while a low signal means an 80 (20)\% chance that it is between 5 and 7 ( 8 and 10). We believe that this is an attractive means of creating noise as one avoids the boundary problems inherent in methods that draw random signals from uniform distributions over a small interval. Additionally, it is very easy to explain to subjects.

We also run a control condition in which all sellers receive full demand information. In all conditions subjects were allowed to submit bids below their costs as well as to withhold units.

\subsection{Our treatments and the conduct of the experiment}

For each of the two auction institutions - uniform (Uni) and discriminatory (Dis) - there are 2 experimental treatments: complete demand information (Comp) and asymmetric demand information (Asym). ${ }^{14}$ Each session consisted of 30 consecutive repetitions

\footnotetext{
${ }^{14}$ In our experiments the uniform price is determined by the highest accepted offer instead of the lowestrejected offer, which is sometimes done in multi-unit auction experiments. The rule we use is the one
} 
(rounds). By letting subjects play many rounds, we made sure that they had the opportunity to gain experience; this seems especially important because the participants in electricity markets are typically experienced professionals. The feedback between rounds included: market price (Uni) or cut-off price (Dis), number of units sold by each of the three competitors, the value of $X$, own revenue, own costs, and own profits. In the discriminatory treatment subjects were told their own units sold and the associated sell prices; competitors' bids and sell prices were not revealed (only the number of units sold).

To reflect the repeated game characteristic of interaction in these market institutions, the same subjects played in the same market throughout the session. We will refer to such a set of subjects as a group. We ran 8 experimental sessions with 16 subjects each. For each treatment there are 8 independent groups of four sellers. ${ }^{15}$ Subjects were told the number of subjects in their group and that they would remain in the same group for all 30 rounds of the experiment. For anonymity reasons, however, subjects were not told with whom of the 15 other session participants they were grouped. The full experimental design is shown in Table 3.

To keep the treatments comparable and to control for sampling errors, we used the same samples of demand realizations in all four treatments. The demand parameter was independently drawn for each round. Each sample was used for one group in each cell, i.e. the realizations of the demand were the same, round by round, for one group of each of the four conditions. We refer to such a set of demand realizations as a set-up.

Table 3: The four cells of the experimental design

\begin{tabular}{ccc}
\hline & Uni & Dis \\
\hline Comp & $(4 ; 8 ; 30)$ & $(4 ; 8 ; 30)$ \\
Asym & $(4 ; 8 ; 30)$ & $(4 ; 8 ; 30)$ \\
\hline
\end{tabular}

in brackets: number of (sellers per group; independent groups; auction rounds) in each treatment

The experiment was conducted in the Laboratori d'Economia Experimental (LeeX) of the Universitat Pompeu Fabra in Barcelona. The software for the experiment was developed using the RatImage programming package (Abbink and Sadrieh (1995)).

typically used in the markets we are interested in (e.g., this corresponds to the system marginal price in the former Pool in England and Wales).

${ }^{15}$ We can treat the individual groups as independent as there is no interaction between subjects of different groups. 
Subjects were recruited by public advertisement in the Department of Economics and were mostly economics students. Each subject was allowed to participate in only one session. In each session, four markets were run in parallel.

At the beginning of each session, subjects were granted a capital balance of 200 talers to which gains were added and from which losses were subtracted. The total earnings of a subject from participating in this experiment were equal to his capital balance plus the sum of all the profits he made during the experiment minus the sum of his losses. A session lasted approximately 2 hours (this includes the time spent to read the instructions). At the end of the experiment, subjects were paid their total earnings anonymously in cash. Because peakload firms had much higher marginal costs than the baseload firms, different conversion rates were used for both types of players. Peakload subjects were rewarded with 4 pesetas per taler, while baseload subjects received one peseta per taler earned in the experiment. Subjects earned on average 2793 Spanish pesetas which is considerably higher than the students' regular wage. 100 pesetas are equivalent to 0.602 euros. At the time of the experiment, the exchange rates to the US dollar and the British pound were approximately $\$ 0.55$ and $£ 0.37$ for 100 pesetas.

\section{Results}

Since bidders in electricity trading institutions are experienced professionals who interact with each other over many auctions, we are particularly interested in the market outcomes and the subjects' bidding behavior towards the end of the experiment. Therefore, we focus our attention on the second half of the experiment (rounds 16-30). The raw data are available from the authors upon request.

Recall that groups constitute the independent observations in our experiment since bidders in the same market interact with each other and are very likely to influence each other's behavior. Therefore, statistical tests that require independence of observations can only be applied on the group level. We test for differences between any two treatments in the following manner. First, we compute the respective test statistic (e.g. the price level) for the single groups. Then, we compute the difference between the two groups that have used the same set of realizations of demand. We then apply the non-parametric binomial test to the eight differences from the eight pairs of observations. This test is very simple to apply: The null hypothesis presupposes that there is no treatment difference and thus the two observations using the same set of demand realizations should, in expectation, have the same test statistic. Differences are solely due to random sampling variations, thus a greater or smaller test statistic for the observation of one or the other treatment is equally likely. Under the null hypothesis, we should observe positive or negative treatment differences in about the same number of observations, and the probability to 
observe seven or eight positive (negative, respectively) differences should occur with a probability lower than 5\%. Therefore, we can reject the null hypothesis when we observe seven or eight observations with a positive (negative, respectively) difference at a significance level of $\alpha=0.05$ (one-sided).

\subsection{Market prices}

Figure 2 plots the evolution of average market prices over the thirty rounds of the experiment; the term 'market prices' refers to the prices actually paid. In the early rounds of the uniform auction, the average price is well above 30 , the highest price at which all the demand is served, indicating that the split of the total surplus is strongly in favor of sellers. However, as subjects become experienced, competition starts having its effect. With increasing experience, we observe market prices quickly falling and ending up below 30. In the discriminatory design, the evolution of average prices takes a quite different path, with prices starting from a much lower level and falling only gently. When subjects are more experienced, however, no substantial differences can be identified between the treatments anymore.

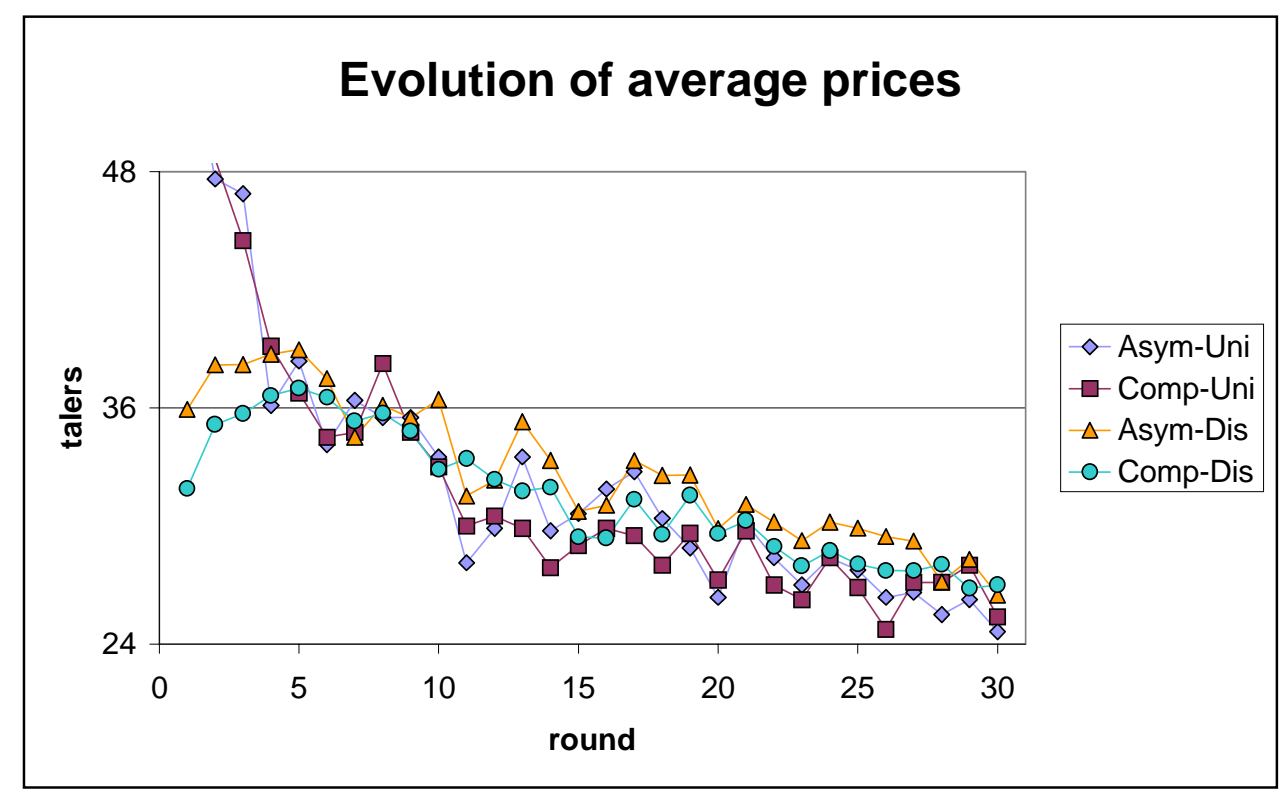

Figure 2

Figure 3 shows the average market prices for the second half of the experiment, separately for the independent observations in the four treatments. Recall that there is always one observation in each treatment matched to one observation in another treatment using the same set of realizations of the basic demand. In no pair wise comparison between two treatments do we observe seven or more average prices of one 
treatment being greater than their counterparts in the other treatment using the same setup. Thus, the binomial test cannot reject the null hypothesis of no treatment differences for any of the pair wise comparisons.

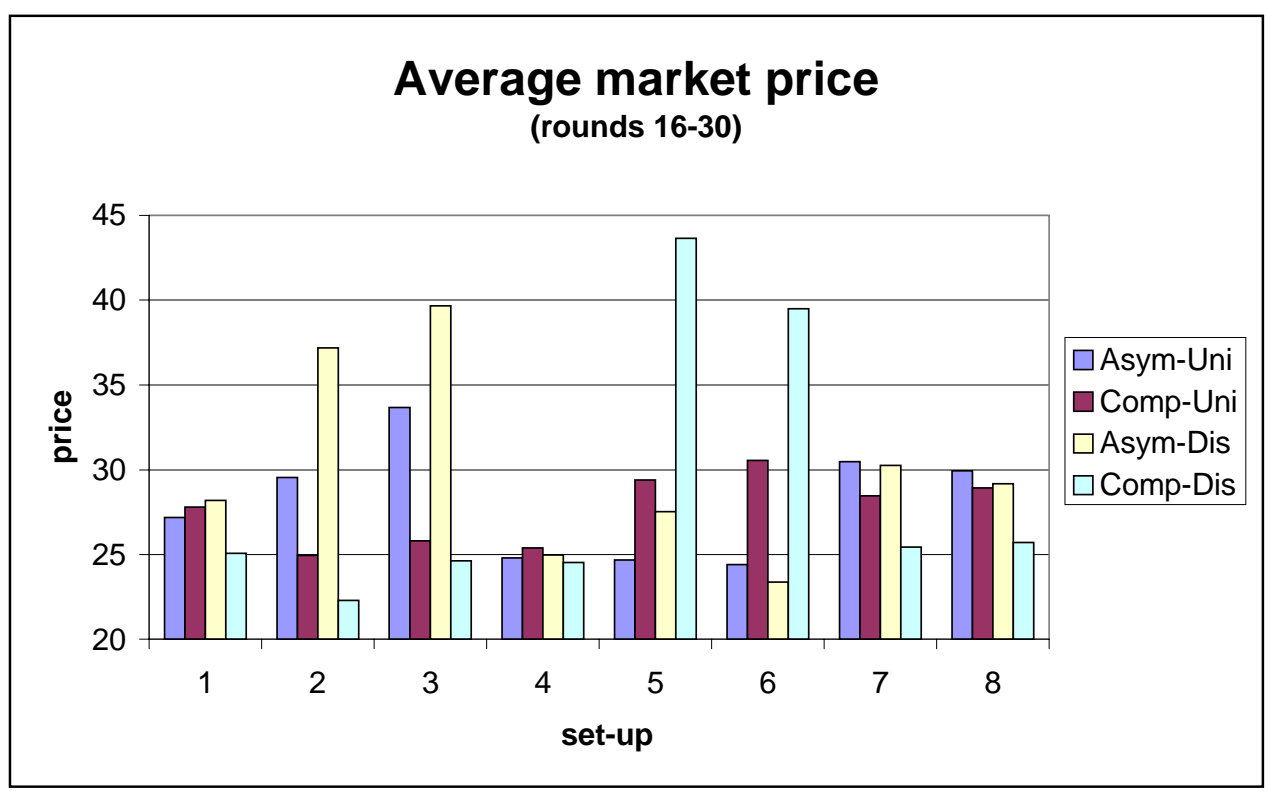

Figure 3

As mentioned, there is a strong tendency towards prices below 30 in the data. The competitive price range - as can be seen from the demand and supply curves depicted in figure 1 - does not change with the basic demand $X .{ }^{16}$ Nevertheless, we observe that average prices tend to be slightly higher when demand is higher. Figure 4 shows the average price as a function of the basic demand, for the aggregate data of each condition separately. Thus, bidding behavior seems to be not so competitive that it would rule out any mark-ups in high demand situations. ${ }^{17}$

\subsection{Price volatility}

Besides average market prices, the choice of an auction procedure may also affect the volatility of prices over time. In our experiment, we measure volatility by the standard deviation of the average price over the second 15 rounds. We do not find evidence for a

\footnotetext{
${ }^{16}$ Unit prices of 25 or more paid to a producer guarantee that no firm incurs total losses. If the unit price is 23 , and a peakload producer happens to sell only one unit, it would face a small loss. Notice that in the paybid auction, bidders can nevertheless make losses if their bids are too low.

${ }^{17}$ Notice that these data lack the necessary requirements to apply statistical tests. Firstly, the observations for different $X$ are not independent from one another. Secondly, different $X$ values may be drawn at different rounds of the experiment, such that effects of $X$ variations on prices may interfere with general price trends. Thus, inference should be drawn with caution.
} 
significant difference in the inter-auction dispersion of average prices in any pair wise comparison of conditions.

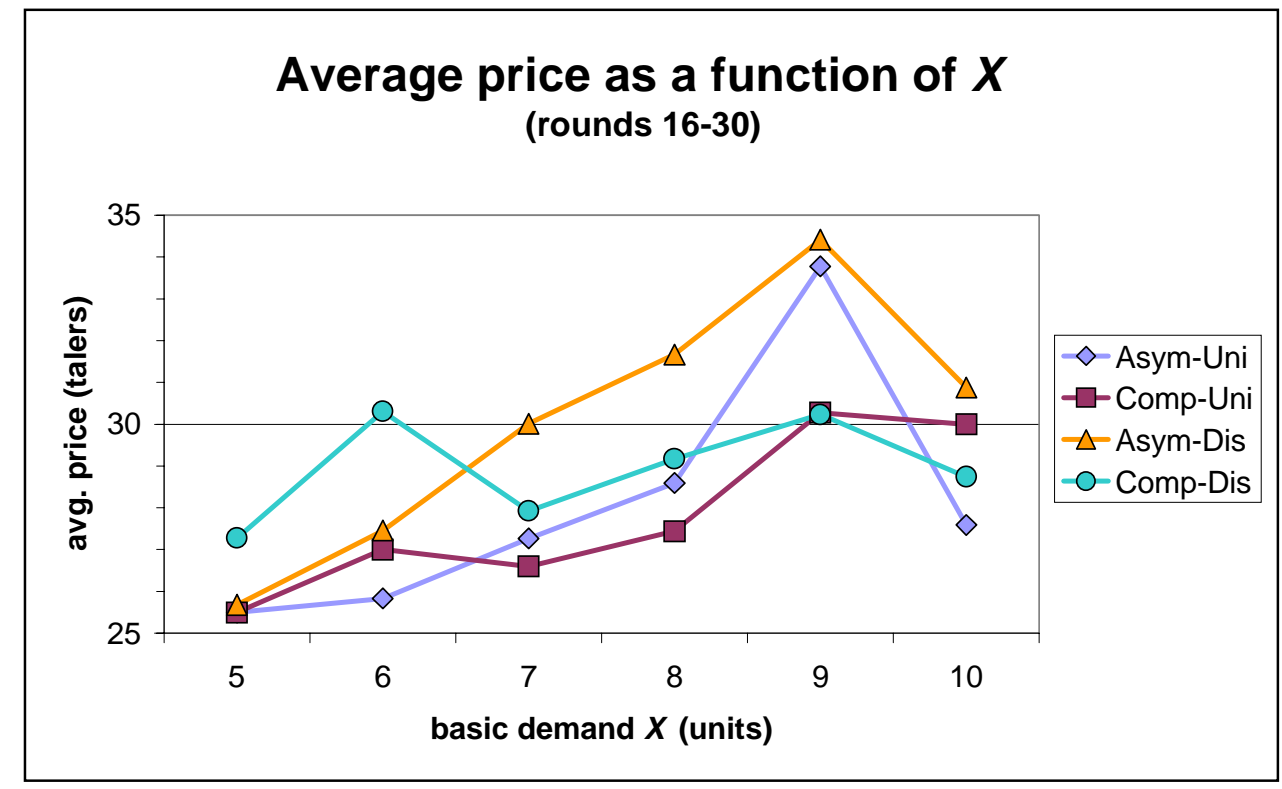

Figure 4

\subsection{Efficiency}

Our primary result from these experiments is that the discriminatory auction is significantly less efficient than the uniform auction when there is asymmetric information. Figure 5 shows the total surplus in the last 15 rounds of the four treatments by subject group. The total surplus is defined as the sum of the consumers' valuations for the sold units minus the total production costs incurred by all sellers together. ${ }^{18}$ In fact, in all eight set-ups the uniform auction scores a higher surplus than the discriminatory auction in the corresponding market, in the presence of asymmetric information. The same comparison for the control condition with full information does not yield a significant difference.

Efficiency losses may arise from different sources. As we have seen, the average market prices are relatively similar in both institutions. However, while in the uniform auction all scheduled sellers pay the same price, the discriminatory auction assigns different prices to different units, such that some prices may well be higher than the unique price would be in the uniform auction mechanism. This, in turn, may induce a tendency towards higher cut-off prices. Higher cut-off prices can reduce the efficiency score since they tend to

\footnotetext{
${ }^{18}$ Recall that the value of a unit to consumers is 100 for the first $X$ units, 55 for the first two units exceeding $X$, and 30 for units exceeding $X+2$.
} 
lead to a lower quantity being sold in the auction. Thus, not all economically possible surplus is extracted from the market.

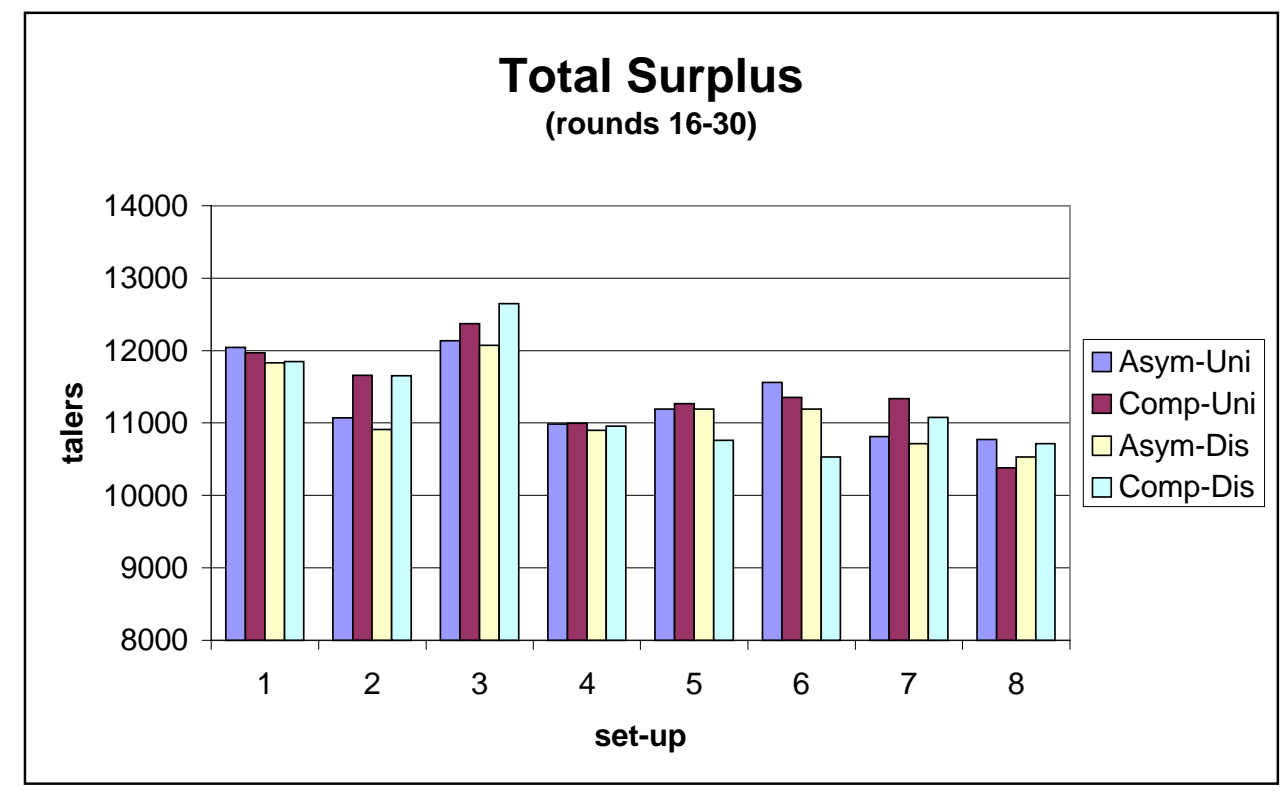

Figure 5

Another possible source of efficiency loss incurred in the discriminatory auction may be the displacement of baseload by peakload generators undercutting their bids (possibly inadvertently since a peakload producer might be bidding on the expectation of a low demand signal whilst the baseload producer knows demand will be high). While in the uniform auction baseload generators can generally make sure to be scheduled by submitting low bids (still being reasonably confident that the market price is eventually determined by peakload bidders when the demand level is sufficient), they face a much harder task in the discriminatory design. In the latter case, decreasing their bids down to their cost level would slash their profit margins to zero. In order to ensure significant profits, they must try not to undercut the bids of the peakload generators too drastically. This response to discriminatory mechanisms may augment the likelihood of displacements, i.e., incidences in which baseload generators are outbid by peakload generators even though the former could produce at much lower costs.

To disentangle these two possible sources of inefficiency, we need to look at both effects separately. Figure 6 shows that in the asymmetric information treatment, in which we observe a significantly lower efficiency in the discriminatory than in the uniform auction, cut-off prices are indeed significantly higher under the pay-bid scheme. This is observed in 7 of the 8 set-ups which is significant at $\alpha=0.05$ (one-sided), according to the binomial test. The difference in the control condition with full information is not 
significant. The higher cut-off prices result in a significantly lower quantity produced (recall that the demand function has a step at the price of 30). In the last fifteen rounds of Asym-Uni, on average 0.35 units less are sold per period than would be efficient, while the corresponding "loss" for Asym-Dis is 0.89. In all five set-ups in which there is a difference between the two observations, the number is higher under the discriminatory format (three set-ups exhibit the same figure for both conditions). This difference is significant at $\alpha=0.05$ (one-sided), according to the binomial test. In the control conditions with full information, the figures are 0.39 for Comp-Uni and 0.54 for CompDis. Here the difference is not significant.

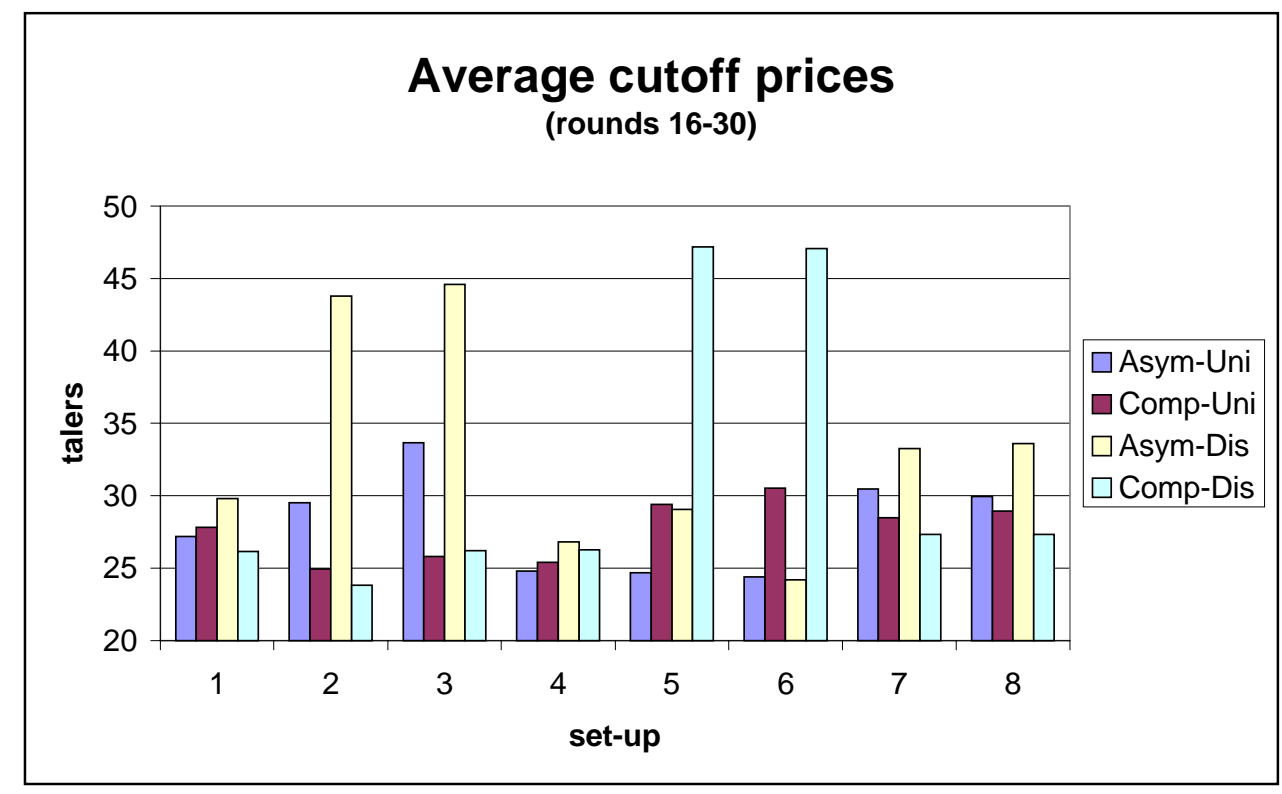

Figure 6

On the other hand, our data do not provide conclusive evidence for more displacements in the discriminatory format. We may define the loss in technical efficiency as the difference between the realized total costs and the minimal costs that would have been incurred by the four firms altogether if they had produced the given number of units in the technically optimal schedule. These losses include losses through displacements of baseload generators and, to a lesser extent, losses that occur when production is not optimally allocated within one type of producers (e.g. optimal allocation may require that one peakload seller produces 4 and the other 0 , but the actual constellation is that one produces 3 and the other 1 so then we get a (small) loss in technical efficiency).

Indeed, the loss in technical efficiency is on average higher in the discriminatory auction than with the uniform auction design, both in the asymmetric information condition (30.7 versus 25.1) and in the control condition with full information (26.1 versus 18.7). 
However, based on the independent observations for the eight set-ups we cannot reject the null hypothesis of no difference, in either of the two information conditions. The differences between the information conditions also point in the expected direction, with technical efficiency losses greater under asymmetric information, but this is also insignificant.

We obtain the analogous result if we look at the number of displacements, without accounting for the cost consequences. On average over the last 15 rounds, 1.36 units are displaced in Asym-Uni, while in Asym-Dis 1.68 units are scheduled to the "wrong" producer. In the control treatment, the corresponding numbers are 1.02 in Comp-Uni and 1.42 in Comp-Dis. Neither of these differences, however, is statistically significant.

To summarize, when there are informational asymmetries among sellers the discriminatory auction proves less efficient than the uniform auction. This reduced efficiency derives primarily from market prices that are more peaky resulting in reduced total surplus. While the volatility of prices are not significantly different, this 'upside' price risk in the discriminatory auction is a feature which increases the regulatory burden of insuring that prices remain below given thresholds. ${ }^{19}$ Although these price spikes wash out on average, they can have implications for suppliers selling retail under regulated prices but having to buy substantial power in the spot market. In England and Wales retail price controls are to be lifted from April 2002 implying that, in areas where retail competition is weak, high spot prices can be passed on to domestic consumers.

\subsection{Profitability}

When bidders have only imprecise and insecure information on the actual demand, one may hypothesize that they face a more difficult job when deciding about their bidding strategy, which leads to lower profits. However, our data do not exhibit a significant difference in average profits across the information conditions, as figure 7 shows. The figure plots the average round profit of the two peakload generators in the second half of the experiment. In five of eight set-ups in the uniform auction and in only two cases under the discriminatory format we observe higher peakload generator profits in the control condition with full information. Thus, the data do not allow us to reject the null hypothesis of equal profit opportunities for peakload generators under either of the auction designs when there is full information.

However, in the case of asymmetric information, peakload producers would prefer a discriminatory auction format, which leads to higher profits for them than observed in the corresponding market using the uniform design. This difference is significant at $\alpha=0.05$ (one-sided) according to the binomial test. 


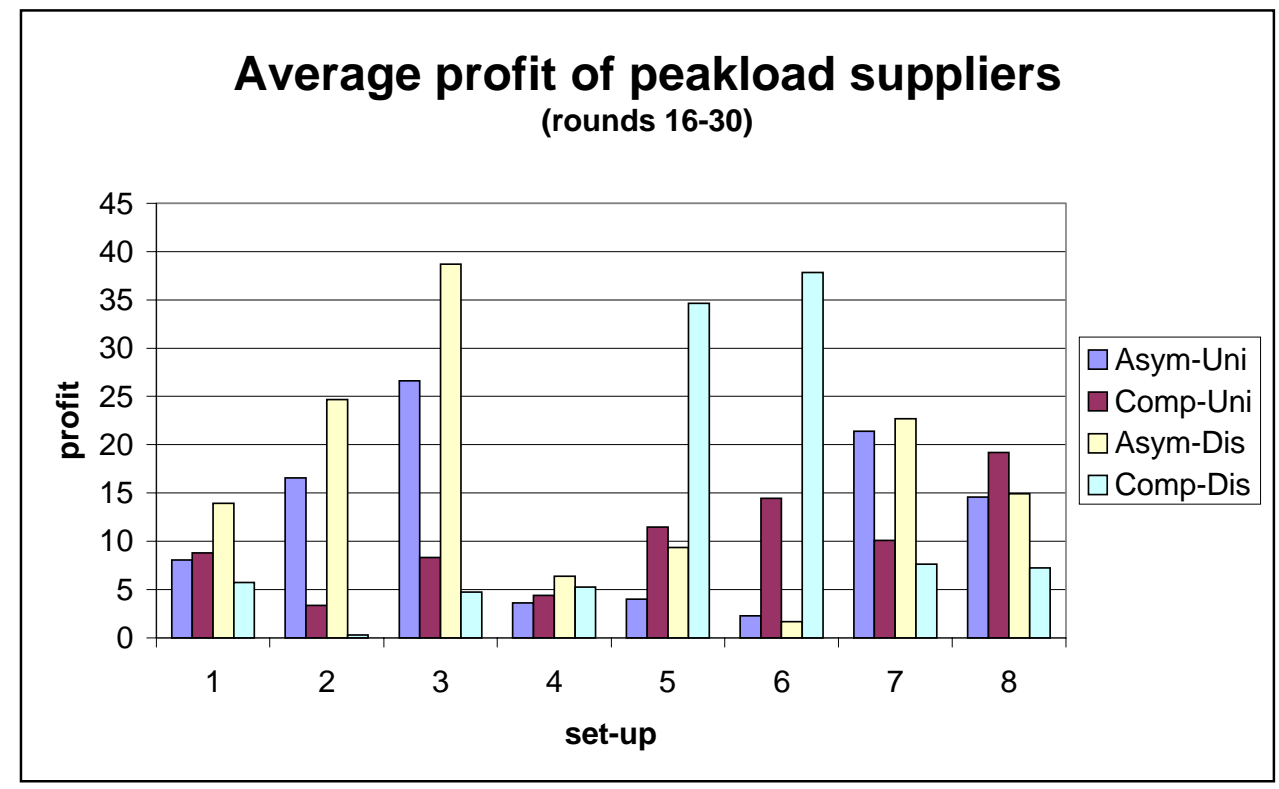

Figure 7

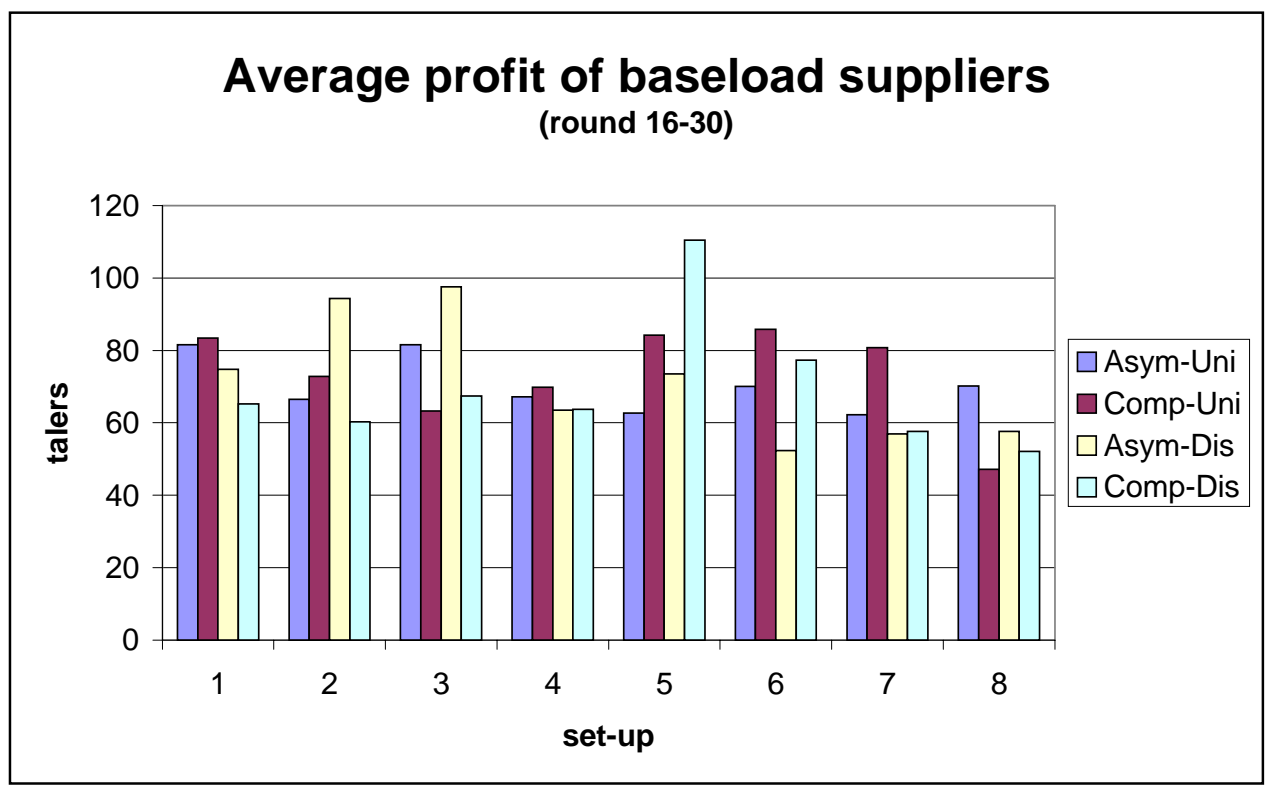

Figure 8

As shown in figure 8 baseload generators do not profit from the discriminatory format in the same way. Here, no pair wise comparison between information treatments nor between auction conditions yields a significant difference.

Why are uninformed peakload generators better off in a pay-bid auction? There seem to be two relevant factors. First, the average market price tends to be very similar in both

\footnotetext{
${ }^{19}$ We would like to thank the anonymous referee for this interpretation.
} 
institutions, as we have seen in earlier sections. However, while the uniform auction specifies a single price for all units, in the discriminatory auction different prices can prevail for different units. Thus, given a very similar average, some units sell at lower, some at higher prices than they would in a uniform auction. In the present setting, this feature tends to favor peakload generators.

This is so because they tend to submit higher bids than the baseload generators. Figure 9 shows the difference in the average bid submitted by the baseload and the peakload producers. With uninformed high cost bidders, we observe a higher average bid of the peakload generators in all eight set-ups. This implies that they tend to sell more often at the prices that are higher than the single price in the uniform auction would be.

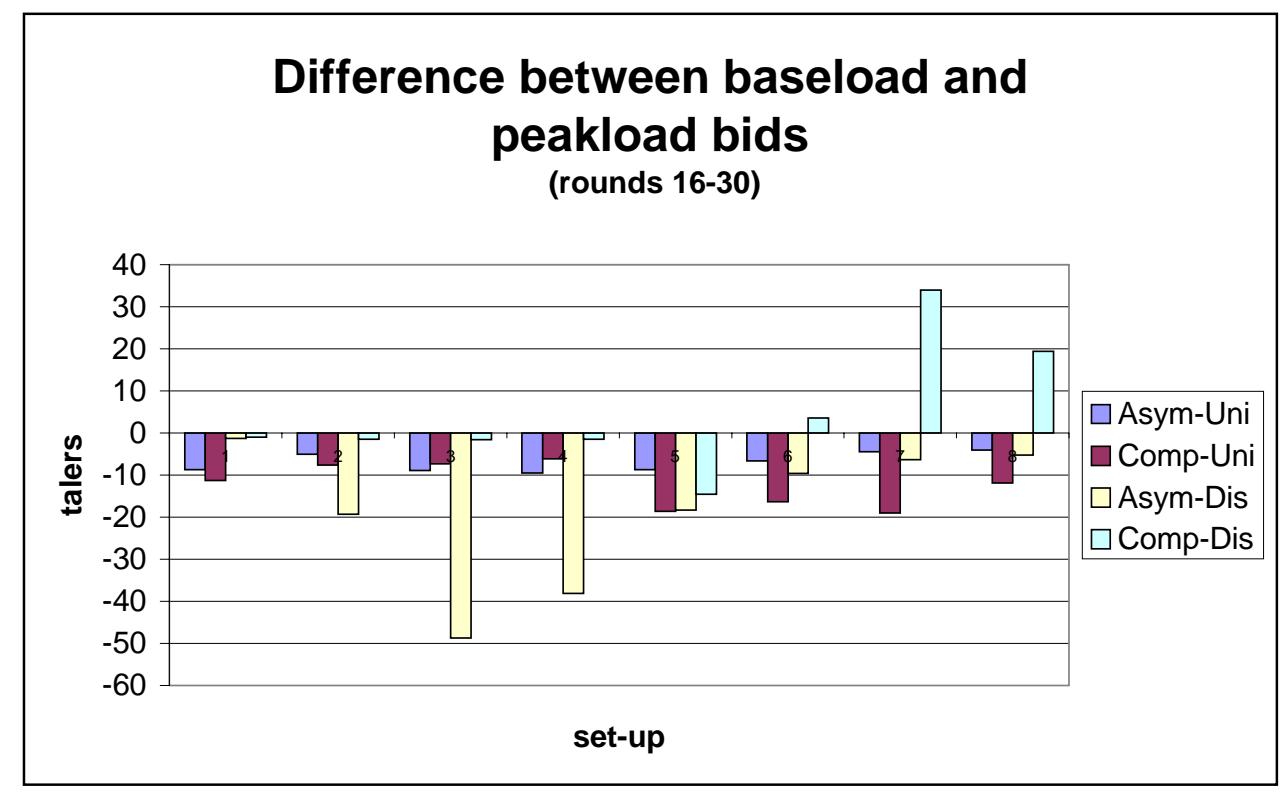

Figure 9

An analogous result for the control treatment with fully informed peakload generators cannot be found, which is consistent with the observation that here peakload operators are not significantly better off in the discriminatory than in the uniform auction.

\subsection{Collusion}

The fear of possible collusive behavior among the bidders is an important issue in the design of trading mechanisms. This concern is fuelled by the repeated game these trading mechanisms inherently establish. The question arises whether collusive behavior can be identified in our data, and whether it is more likely to occur in one of the trading mechanisms. Our data do not allow us to answer this question in a conclusive way. Collusive behavior should express itself in sustainable high market prices. Figure 3 
indeed shows that in some markets average market prices are extraordinarily high (setups 5 and 6 in Asym-Dis, or set-ups 2 and 3 in Comp-Dis). Interestingly, the four markets with the highest average market prices are all found in the discriminatory treatment, which may suggest that the discriminatory format is more susceptible to collusion than the uniform auction. However, these occurrences are still too sparse to judge whether the discriminatory format systematically encourages collusive behavior in an environment like the present.

\section{Conclusions}

Restructuring of electricity industries has created a more decentralized market place where agents of different sizes, incumbency, and levels of vertical integration compete to buy and sell power. In some markets (for example, England and Wales) demand forecast which were once primarily the responsibility of one central agent are increasingly being made at the company level. The required drain on company resources to meet this new responsibility is not equal for all companies and one might therefore expect that the degree of forecast accuracy will likewise vary among them. Debates on industry restructuring regularly fail to address the issue of such informational asymmetries among agents even though policy makers generally claim to be in favor of non-discriminatory market rules.

In England and Wales the movement toward more decentralized demand forecasting has been accompanied by a change from uniform payments to generators to discriminatory payments. As in other contexts (such as the sell of treasury bills) the desirability of discriminatory versus uniform pricing in the electricity industry has been debated.

In this paper, we use laboratory experiments to compare outcomes such as prices, profitability, and efficiency when sellers are asymmetrically informed about market demand. We make these comparisons under two different payment rules for sellers: uniform prices and discriminatory prices. We do not find a significant effect when we look at average prices under the two pricing rules, but efficiency is significantly lower with discriminatory prices when the market is populated by asymmetrically informed sellers. We observe that the cut-off prices - which determine the marginal unit to be traded - are significantly higher under the pay-bid scheme. Thus, the discriminatory auction is more likely to leave part of the possible surplus unrealized and create more price peaks relative to uniform pricing. The beneficiaries are the high cost peaking stations who profit from higher cut-off prices.

We do not obtain significant results between the uniform and discriminatory auctions when there is full demand information for both high and low cost sellers. The efficiency and profitability differences only arise when there is asymmetric information. This alone 
gives reason for further research and debate in the electricity industry taking fully into account the informational differences that exist among agents. Moreover, our results do not support the claim often made in favor of discriminatory pricing that consumer prices will be lower and less volatile. We find no significant difference in average prices or volatility under the two pricing rules, and price spikes are more frequent with discriminatory pricing when information is asymmetric. Finally, our results lend some support to the argument made by Kahn et al. (2001) that discriminatory auctions can result in inefficient dispatch.

\section{References}

ABbink, Klaus, Jordi BrAndTs, and Paul PEZANIS-Christou (2002), "The Spanish Auctions for Government Securities: A Laboratory Analysis," WP Institut d'Anàlisi Econòmica, Barcelona.

ABBINK Klaus, and Abdolkarim SADRIEH (1995), "RatImage - Research Assistance Toolbox for ComputerAided Human Behavior Experiments," SFB Discussion Paper B-325, University of Bonn.

Goswami G., T.H. NoE and M.J. Rebello (1996), "Collusion in Uniform-Price auctions: Experimental evidence and implications for Treasury auctions", The Review of Financial Studies, 9:3, 757-785.

GREEN, Richard and Tanga MCDANIEL (1999), "Modeling the Review of the Electricity Trading Arrangements: a model of forward trading and the balancing mechanism," Department of Applied Economics Working Paper, 0003(a).

KAGEL, John and Dan LEVIN (2001), "Independent Private Value Multi-Unit Demand Auctions: Experiments with Uniform Price and Dynamic Vickrey Auctions," Econometrica, 69, 413-454.

KAHN, Alfred, Peter CRAMPTON, Robert PORTER and Richard TABORS (2001), "Pricing in the California Power Exchange Electricity Market: should California switch from uniform pricing to pay-as-bid pricing?" Blue Ribbon Panel Report commissioned by the California Power Exchange, January 23. Also published in The Electricity Journal, July 14, no 6, 2001.

MCCABE, Kevin, Stephen RASSENTI and Vernon SMiTH (1990), "Auction Institutional Design: Theory and Behavior of Simultaneous Multiple-Unit Generalizations of the Dutch and English Auctions," American Economic Review, 80, 1276-1283.

Miller, Gary and Charles Plott (1985), "Revenue-Generating Properties of Sealed-Bid Auctions: An Experimental Analysis of One-Price and Discriminative Processes", in V. Smith (ed.), Research in Experimental Economics, 3, Greenwich, CT: JAI Press, 159-181.

OFFER (1998), Review of Electricity Trading Arrangements: Interim Conclusions.

OFFER (1999), The New Electricity Trading Arrangements: Vol. 1.

RASSENTI, Stephen, Vernon SMITH and Bart WILSON (2000), "Controlling Market Power and Price Spikes in Electricity Networks: demand-side bidding," WP University of Arizona.

RASSENTI, Stephen, Vernon SMITH and Bart WILSON (2001), "Discriminatory Price Auctions in Electricity Markets: Low Volatility at the Expense of High Price Levels," WP University of Arizona.

Staropoli, Carine, Dominique FinOn, Jean-Michel Glachant, Céline Jullien, Richard QuATrain, Stéphane ROBIN and Bernard RUFFIEUX (2000), "Modifying industry structure or market institution? An experimental analysis of the reform of the english electricity pool," WP Université Paris I.

TELSER, Lester (1978), "Economic Theory and the Core," University of Chicago Press.

VAN BoEnING, Mark and Nathaniel WilcoX (1996), "Avoidable Cost: Ride a Double Auction Roller Coaster," American Economic Review, 86, 3, 461-477.

VICKREY, William (1961), “Counterspeculation, auctions, and competitive sealed tenders," Journal of Finance, Vol. 16, 8-37. 


\section{Appendix I. Instructions}

(translated from the Spanish original)

This is the version for the Asym-Disc treatment. The differences with respect to the instructions for the other treatments are indicated in brackets.

\section{General information:}

Thank you for showing up for the experiment. In this experiment there will be 30 rounds. In each of these rounds you will participate in a market in which you will be one of the sellers of a fictitious good. In each round you will be in a group with another three participants. The groups will remain constant during the 30 rounds.

\section{Decisions of the sellers:}

In each round each seller will be able to make selling price offers for a number of units of a good. The selling offers may be different for different units. The selling offers will be made separately by each seller. During each round of the experiment each seller will be able to sell between 0 and 4 units. Each seller will have costs which will depend on the number of units that he sells.

With respect to costs there will be two types of sellers. Two of the four sellers in each group will be of type $A$ and will have the following costs:

\section{Number of units sold:}

0

1

2

3

4 $\underline{\text { Total costs incurred: }}$

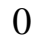

14

15

20

25

Observe that for each number of units total costs are shown. This means that, for instance, the total cost of producing 3 units is 20 .

The other two sellers in a group will be of type $B$ and will have the following costs:

Number of units sold:

1

2

3

4
Total costs incurred:

0

25

46

92

\section{Decisions of the buyers:}

In this experiment the decisions of the buyers will not be made by participants in the experiment, rather they will be made by the computer. The decisions that the computer will make for the buyers are the following. In each round the computer will make buying price offers for $\mathrm{X}$ units at a price of 100, for another two units at the price of 55 and for another two units at a price of 30 .

\section{Information about the quantity $\mathrm{X}$ :}

At the beginning of each round the quantity $\mathrm{X}$ will be determined randomly. $\mathrm{X}$ will be, with equal probability, one of the six whole numbers $5,6,7,8,9$ or 10 . (In the treatments with complete information the rest of this section was replaced by the following sentence: "At the beginning of each round the sellers will be informed about the exact value of X." ). At the beginning of each round the sellers will receive information about the value of $X$. This information will be different for the sellers of type A than for the sellers of type B. The sellers of type A will be informed of 
the exact value of $X$. The sellers of type $B$ will not be informed of the exact value of $X$, rather they will receive an estimate of $\mathrm{X}$. They will receive the information that $\mathrm{X}$ is:

- low, i.e., with equal probability 5,6 or 7 or that it is

- $\quad h i g h$, i.e., with equal probability 8,9 or 10 .

In addition, this estimate will not be true with a probability of $100 \%$, but only of $80 \%$. This means that when $X$ is 5,6 or 7 a seller of type B will receive with an $80 \%$ probability an estimate that $X$ is 5,6 or 7 and with a probability of $20 \%$ an estimate that $X$ is 8,9 or 10 . In the same way, if $X$ is 8,9 or 10 then a seller of type $B$ will receive with an $80 \%$ probability the estimate that $X$ is 8,9 or 10 and with a probability of $20 \%$ the estimate that X is 5, 6 or 7. Each seller of type B will receive his/her estimate separately.

\section{The market rules:}

We will now explain how it is determined which units will be exchanged in a market round and at which price.

In each round we will order the selling price offers from smaller to larger for each group of four sellers. This means that for each group the first unit that will be offered for sale will be the one corresponding to the lowest selling offer. The second unit that will offered for sale will be the second lowest and so on. If several units are offered at the same price they will be ordered randomly. An example of an ordering of selling offers can be seen in figure 1.

In each round we will order the buying offers from larger to smaller. This means that the first buying offers will be those of the $X$ units at 100. After that we will order the buying offers of the two units at 55 and then those of the two units at 30. This ordering of buying offers can be seen in figure 2 .

For each round the price and the units sold will be determined in the following way. Starting from the ordering of selling offers from smaller to larger and from that of buying offers from larger to smaller, all those units will be sold for which the selling offer is not larger than the buying offer and the prices received for each of the units will be the ones corresponding to the selling offers of each of those units. (In the uniform auction treatments this last part of the sentence was replaced by the statement: "... and the price that will be received for each of the units sold, called market price, will be the one corresponding to the last unit sold."). The price corresponding to the selling offer of the last unit sold will be called the cutoff-price.

Graphically the units sold are given by the intersection between the orderings of the selling offers and of the buying offers. An example can be seen in figure 3. (For the uniform auction treatments the last sentence was replaced by: "Graphically the units sold and the price that will be received are given by the intersection between the orderings of the selling offers and of the buying offers. An example can be seen in figure 3.").

The cutoff price and the units sold will depend of the selling offers made by the four sellers of a group and on the randomly determined value of X. (For the uniform auction treatments the term 'cutoff price' was replaced by 'market price').

\section{Profits and losses:}

Your profit or loss in a round will be equal, for the units that you have sold, to your selling offers, each of them multiplied by the number of units sold minus the cost corresponding to the number of units that you have sold. (For the uniform auction treatments the last sentence was replaced by: "Your profit or loss in a round will be equal to the market price multiplied by the number of units sold minus the cost corresponding to the number of units that you have sold.").

Information that you will receive:

At the end of each round you will be informed about the cutoff price (market price in the uniform auction treatments), about the number of units sold by each of the sellers, about your earnings and about the exact value of X (unknown to sellers of type B at the moment at which they make their offers). (The statement in brackets was eliminated for the treatments with complete information). 


\section{Payment:}

The currency used in this experiment is the taler, so that all the buying and selling offers and all the prices will be in talers. At the beginning of the experiment each seller will receive a capital balance of 200 talers. Your total earnings from your participation in this experiment will be equal to the sum of all your profits and your capital balance minus your losses. If at any moment in the experiment your earnings became negative you will not be allowed to continue participating in the experiment. At any moment in the experiment you will be able to check your total earnings in talers on the screen. At the end of the experiment your total earnings will be converted into pesetas. For sellers of type A the exchange rate will be 1 peseta per taler. For sellers of type B the exchange rate will be 4 pesetas per taler.

From this moment on any kind of communication with other participants is not allowed. If you have a question, please, raise your hand and one of us will come to your table to answer it.

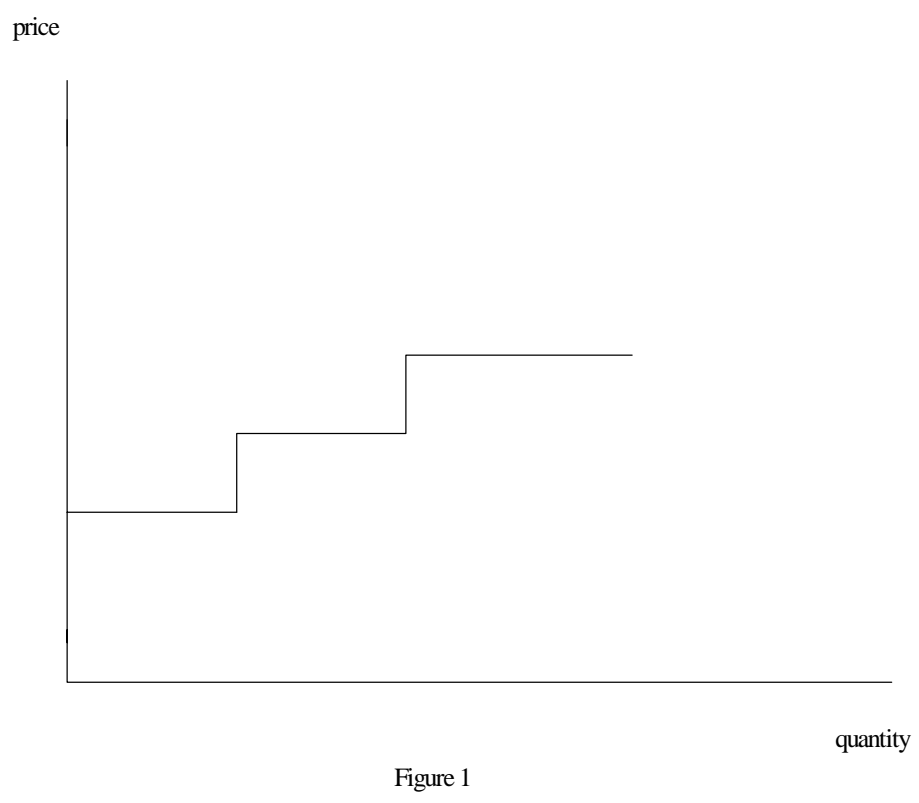




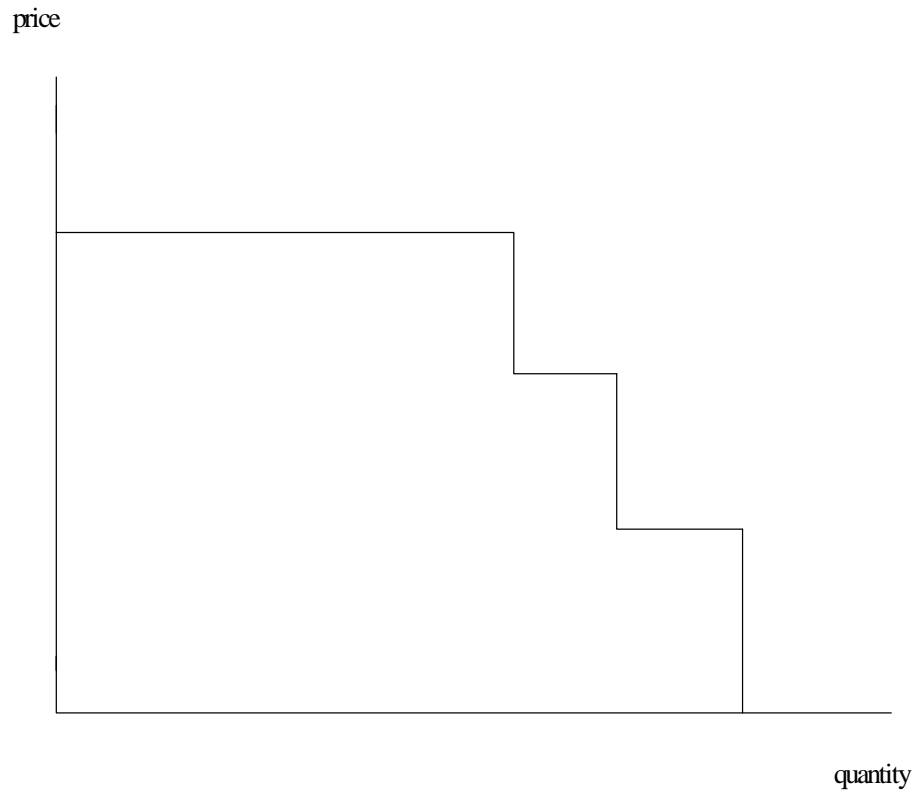

Figure 2

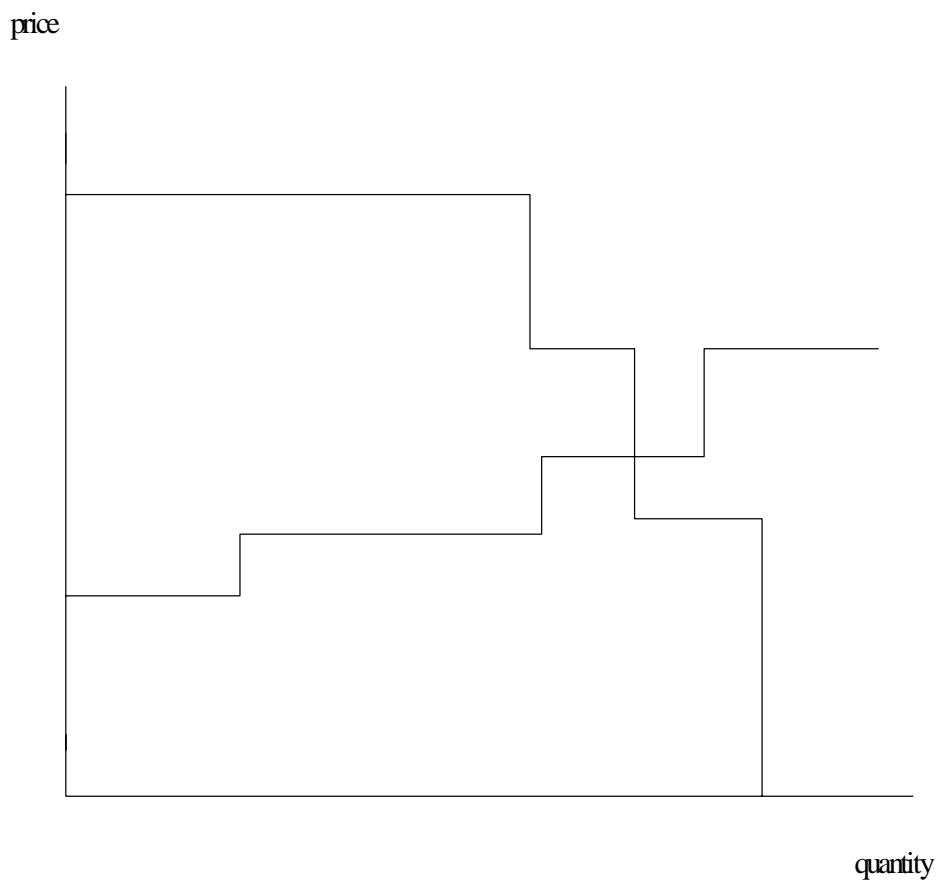

Figure 3 